Received: April, 2016

Accepted: November, 2016

ISSN $2006-6996$

\title{
THE EFFECT OF WATER SOLUBLES ON KELVIN EFFECTS OF THE MARITIME POLLUTED AEROSOLS
}

\author{
*Galadanci ${ }^{1}$, G.S.M., Tijjani $^{1}$, B. I., Uba $^{2}$, S., Abubakar ${ }^{3}$, A.I., Adamu ${ }^{1}$, I.D. and Nura, A. M. ${ }^{1}$ \\ ${ }^{1}$ Department of Physics, Bayero University, Kano. NIGERIA. \\ ${ }^{2}$ Department of Physics, Ahmadu Bello University, Zaria. NIGERIA \\ ${ }^{3}$ Department of Physics, Kano University of Science and Technology, Wudil. NIGERIA \\ Corresponding author:*gsmgalad@yahoo.com; idrith@yahoo.com, idrithtijjani@gmail.com; 08037260380
}

\begin{abstract}
In this work microphysical properties of Maritime Polluted aerosols wereextracted from Optical Properties of Aerosols and Clouds (OPAC) after varying the concentrations of water soluble at five different levels. The analytical expressions for the changes in the equilibrium relative humidity (RH), effective radii, effective hygroscopic growth, their magnitudes and fractional changes on the effects of surface tension (the Kelvin effect) on the ambient aerosols were numerically analyzed. The expressions were applied to two - one parameter models. It was discovered that the increase in water soluble concentration caused decreased in the Kelvin effects which implies decrease in surface tension. The numerical analysis of the data showed that to the lowest order error. Increase in the overestimation of the effective hygroscopic growth and decrease in the overestimation of the effective radii. On the two models applied, we discovered that the fractional changes in hygroscopic growth increase in overestimation while there is decrease in overestimation of fractional changes in effective radii. Finally, decrease in the underestimation of the fractional changes in the equilibrium pressure it was discovered.

Keywords: Kelvin effect, effective radius, effective hygroscopic growth, water soluble, ambient Relative Humidity, overestimation.
\end{abstract}

INTRODUCTION

In the real atmosphere, RHis the main component of atmospheric aerosols and its amount depends on the particlesphysical and chemical compositions and their effective sizes. The growth of aqueous droplets in humid air is commonly described by Köhler theory (Kohler, 1936; Gysel et al., 2002; Kreidenweis et al., 2005, Tijjani et al, 2015). It states that the ambient $\mathrm{RH}$ equals the product of water activity for a plane solution surface, and that of the Kelvin effect of the curved surfaces such as aerosol particles. The water activity considers the lowering of the equilibrium vapor pressure with increasing solute concentration at a given $\mathrm{RH}$, is complemented by the Kelvin-term, which accounts for the increase in the water vapor pressure due to the curvature of the particle surface. The Kelvin factorwhich causes the increase in the surface energy with the decreasing particle diameter (Russell \& Ming, 2002), causes the hygroscopic growth to decrease with decreasing dry size for particles of identical composition, depending on $\mathrm{RH}$, chemical composition, and the RH history of the particles(Martin,2000).Water soluble organic and inorganic can make up an important fraction of atmospheric aerosols. They can dominate the CCN activity and hygroscopic growth depending on chemical compositions (Laaksonen et al.,1998; Nenes et al., 2002; Anttila and Kerminen, 2002; Kreidenweis et al., 2006; McFiggans et al. 2006; Sun and Ariya 2006) by enhancing the Raoult effect and particle size (Kelvin effect; Thomson, 1871).Water-soluble aerosol particles grow by condensation of water vapor simply because the water activity of the aqueous solution strives to equilibrate to the $\mathrm{RH}$ in the surrounding air in accordance with the Köhler equation. The Kohler theory presented the theory of cloud condensation nuclei (CCN) activation of atmospheric aerosol particles as the activation due to the thermodynamic balance of two effects: a decrease in water vapor pressure due to the solute (Raoult effect) and an increase in water vapor pressure due to the curvature at the air-liquid interface (Kelvin effect). These two effectsare the major parameters that made hygroscopic growth to be size and composition dependent.

The modern concepts of Kohler equations enable the determination of the equilibrium size of an aerosol droplet for a given dry size, chemical composition, $\mathrm{RH}$ and Temperature, by accounting for the dissolution of gases into droplets, changes in surface tension, ion charges, or density of the droplet solutions (e.g. Russell and Ming, 2002; Mikhailov et al., 2004; Biskos et al., 2006a, b; Seinfeld and Pandis, 2006; McFiggans et al., 2006; Rose et al., 2008; Mikhailov et al., 2009; Ruehl et al., 2010) which is always smaller than the ambient $\mathrm{RH}$.

In this paper some microphysical properties of maritime polluted aerosols were extracted from OPAC by varying the concentrations of water soluble at relative humidities of $0,50,70,80,90,95,98$ and $99 \%$ to determine the effects of water soluble on Kelvin effectand water activity on these aerosols.

The microphysical properties extracted are the radii of the aerosols and volume mix ratios and were used to determine the effective hygroscopic and effective radii of the mixtures. 


\section{BAJOPAS Volume 9 Number 2 December, 2016}

The analytical expressions derived by Lewis (2006) for the decrease in the equilibrium radius of a solution drop due to the Kelvin effect with dependences on surface tension, particle size and the estimates for the magnitude of these effects in various situations are numerically analyzed.The analytical expressions derived by Lewis (2006) for the changes in the equilibrium radius of solutions drops, the hygroscopic growth, estimates in the changes of their magnitudes and their fractional changes due to the Kelvin effect with dependences on surface tension, particle sizes are also numerically analyzed.We then applied the expressions to two known one parameter models. They are the power law dependence ( $\gamma$-model) and the model as proposed by Petters and Kreidenweis (2007).

Though in our paper, Tijjani, et al (2015), we discovered that, the Kelvin effect and its consequences on the atmospheric aerosol depends on the hygroscopicity of the aerosol but in this work, we want to determine the effect of varying only the water soluble part.

\section{METHODOLOGY}

The water-soluble part of aerosol particles originates from gas to particle conversion and consists of various kinds of sulfates, nitrates, and other, also organic, water-soluble substances. The soot component is used to represent absorbing black carbon. Carbon is not soluble in water and therefore the particles are assumed not to grow with increasing relative humidity. Sea-salt particles consist of the various kinds of salt contained in seawater. Two sea-salt modes are given as sea salt accumulation and sea salt coarse modes (Koepke et al. 1997).

The equilibrium water vapor saturation ratio $\mathrm{S}$ asdescribed by Kohler theory is given as

$$
\mathrm{S}=\mathrm{a}_{\mathrm{w}} \mathrm{K}_{\mathrm{e}}
$$

(1)

where $a_{w}$ denotes the water activity or Raoult term, and $\mathrm{K}_{\mathrm{e}}$ is the Kelvin effect.

The relationship between droplet radius and $\mathrm{RH}$ at equilibrium can also be given as:

$$
s=a_{W} \exp \left(\frac{2 \sigma w_{w}}{R T r(s)}\right)
$$

wherev $v_{w}$ is the partial molar volume of water, $\sigma$ is the surface tension of the solution at the composition of the droplet, $R$ is the universal gas constant, $T$ is the temperature and $r(S)$ is the equilibrium radius.

For single-solute particles, the equilibrium water vapor saturation ratio $\mathrm{S}$ for a droplet can be described by (Mochida et al., 2006):

$$
\ln s=\frac{A}{r(s)}-\frac{B r^{3}(s=0)}{r^{3}(s)-r^{3}(s=0)}
$$

where $A=\frac{2 \sigma v_{w}}{R T}$ and $B=w \phi \frac{v_{w}}{v_{s}}$ are assumed to be constant, $r(s)$ and $r(s=0)$ are the effective radii of the solute or the volume equivalent effective radii of the wet and dry solute, respectively, $\mathrm{S}$ is taken for seven values $50 \%, 70 \%, 80 \%, 90 \%, 95 \%, 98 \%$ and $99 \%$. $\sigma$ is the surface tension of the solution, $w_{w}$ and $v_{s}$ are the molar volumes of pure water and solute, respectively, $v$ is the degree of dissociation, and $\phi$ is the osmotic coefficient. The product of $v$ and $\phi$ is equivalent to the so-called van't Hoff factor (Pruppacher and Klett, 1997), R and T are the gas constant and temperature, respectively.

But atmospheric aerosols usually comprised mixtures of soluble and insoluble components, therefore the information on the hygroscopicity modes was merged into an "over-all" or "bulk" or "effective" hygroscopic growth factor of the mixture, $\mathrm{g}_{\text {eff }}(\mathrm{S})$, representative for the entire aerosols particle population as:

$$
g_{\text {fff }}(s)=\left(\sum_{k} x_{k} g_{s}^{3}(s)\right)^{1 / 4}
$$

The effective or volume equivalent radius of the mixture was determined using the relation

$$
r_{k f f}(s)=\left(\sum_{k} x_{k} r_{k}\right)^{1 / a}
$$

where the summation is performed over all compounds present in the particles and $x_{k}$ represent their respective volume fractions, using the Zdanovskii-Stokes-Robinson relation (ZSR relation; Sjogren et al., 2007; Stokes and Robinson, 1966; Meyer et al., 2009; Stock et al., 2011).

For multi components, equation (3) can be written to represents the property of the bulk components using equations (4) and (5) as:

$$
\ln s=\frac{A}{r_{\text {eff }}(s)}+\frac{B}{1-g_{\text {fff }}(5)}
$$

using multiple regression analysis with SPSS 16.0 for windows, the constants $A$ and $B$ were determined. The first term on the right hand side of equation (6) can replace the first term of equation (3) as

$$
n K_{R}=\frac{2 v_{w}}{\operatorname{RTr}_{\text {eff }}(S)}=\frac{r_{R}}{r_{\text {eff }}(S)}=g_{a}\left(r_{e f f}(S)\right)
$$

This implies

$$
\begin{aligned}
& K_{e}=\exp \left(g_{a}\left(r_{e f f}(s)\right)\right) \\
& \text { (7b) }
\end{aligned}
$$

wherea characteristic length for the effect of surface tension on the mixture or the effective Kelvin radius $r_{n}=\frac{2 \psi_{w} G}{R T}=A$

$g_{\sigma}\left(r_{\text {eff }}(s)\right)=\frac{r_{k}}{r_{\text {eff }}(s)}=\frac{A}{r_{\text {eff }}(s)}$.

and

The second term on the right hand side of equation (6) can also replace the second term of equation (3) as

$$
\ln _{w}=\frac{b}{1-g_{w f}^{3}(S)}
$$

The lowest correction on the effective hygroscopic growth due to the Kelvin effect was also obtained by Lewis (2006) as:

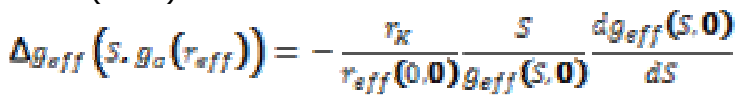


Similarly, the lowest-order correction to the effective radii due to the Kelvin effect was determined by Lewis (2006) as:

$$
\Delta r_{i f f}\left(s, g_{\sigma}\right)=-r_{k} \frac{s}{g_{e f f}\left(s_{i}, 0\right)} \frac{d g_{e f f}(s, 0)}{d 5}
$$

Thedata extracted from OPAC werethen applied to two models equations to determine the effect of water solubles on the Kelvineffects of the models.

The first model is a one-parameter power law,the empirical $\gamma$-model that is frequently used in literature and researchers (Swietlicki et al., 2000; Birmili et al., 2004; Kasten, 1969; Gysel et al., 2009, Putaud, 2012; Tijjani, 2013a;Tijjani, and Uba, 2013a;Tijjani and Uba, 2013b, Tijjani, 2013b;Tijjani et al., 2013) to describe the hygroscopic growth of atmospheric aerosol particles as

$$
g_{\pi f f}(5,0)=(1-5)^{-n}
$$

The exponent $n$ was determined using regression analysis with SPSS 16.0.

Theerrors due to Kelvin effect on equation (13) were determined by substituting this equation into equations (11) and (12), Lewis (2006) as:

$$
\Delta g_{\text {eff }}\left(s_{g_{\sigma}}\left(r_{\text {eff }}\right)\right)=-\frac{r_{H}}{r_{\text {eff }}(0)} \frac{n s}{1-s}
$$

and

$$
\Delta r_{\text {eff }}\left(s \cdot g_{\sigma}\left(r_{\text {eff }}\right)\right)=-r_{k} \frac{n s}{1-s}
$$

The fractional changes in the effective hygroscopic growth and effective radii due to the Kelvin effect error from equations (14) and (15) weredetermined as

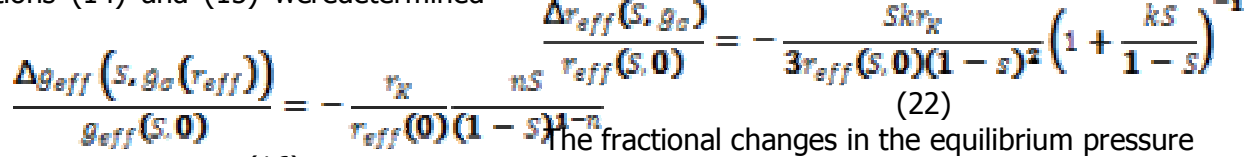

and

$$
\frac{\Delta r_{\text {eff }}\left(s, g_{\sigma}\right)}{r_{\text {eff }}(5,0)}=-\frac{r_{k i}}{r_{\text {sff }}(s)} \frac{n s}{1-s}
$$

The second model is the relation between $\mathrm{g}_{\text {eff }}(\mathrm{S}, 0)$ and $\mathrm{S}$ that has been parameterized in a good approximation by a one-parameter equation, proposed e.g. by Petters and Kreidenweis (2007) and used by some researchers (Tijjani, 2013a;Tijjani, and
Uba, 2013a;Tijjani and Uba, 2013b, Tijjani, 2013b;Tijjani et al., 2013) as:

$$
g s f\left(s_{i} 0\right)=\left(1+n \frac{s}{1-s}\right)^{\frac{1}{2}}
$$

The values of $k$ were determined using regression analysis using SPSS 16.0. The coefficient $k$ is defined as the effective tendency for the ensembles to absorb water (Petters and Kreidenweis, 2007; Sullivan et al., 2007). It accounts not only for the reduction of water activity by the solute but also for surface tension effects (Rose et al., 2008; Gunthe et al., 2009) and depends on the molar volume and the activity coefficients of the dissolved compounds (Christensen andPetters, 2012).

The errors due to Kelvin effects on equation (18) were determined by substituting this equation into equations (11) and (12)as:

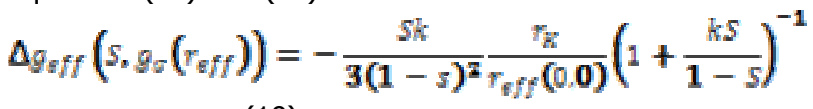

and

$$
\Delta r_{i f f}(s, g s)=-\frac{5 k r_{R}}{\mathbf{3}(\mathbf{1}-s)^{\mathbf{2}}}\left(1+\frac{k s}{\mathbf{1}-5}\right)^{-\mathbf{1}}
$$

The fractional changes in the effective hygroscopic growth and effective radii due to the Kelvin effect error from equations (19) and (20) were determined as

$\frac{\Delta g_{e f f}\left(s, g_{\sigma}\left(r_{e f f}\right)\right)}{g_{t f f}\left(s_{i} 0\right)}=-\frac{s k}{3(1-s)^{2}} \frac{r_{k f}(0,0)}{r_{e f}}\left(1+\frac{k s}{1-s}\right)^{-4 / 3}$ (21)

$s\left(g_{a f f} \cdot g_{\sigma}\left(r_{a f f}\right)\right)$ due to the Kelvin effect error on equation (9) were determined as

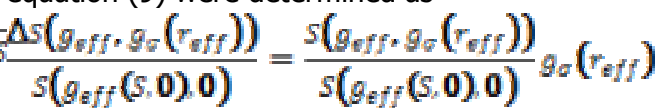
where $s\left(g_{e f f}(s, 0) 0\right)$ is the ambient RH.

RESULTS AND DISCUSSIONS

The models extracted from OPAC are given in Tables 1 and 2 .

Table 1 Compositions of aerosols types (Hess et al., 1998).

\begin{tabular}{|l|r|r|r|r|r|}
\hline Components & \multicolumn{1}{|l|}{$\begin{array}{l}\text { ModelA } \\
\text { Con. }\left(\mathrm{cm}^{-3}\right)\end{array}$} & $\begin{array}{l}\text { ModelB } \\
\text { Con. }\left(\mathrm{cm}^{-3}\right)\end{array}$ & $\begin{array}{l}\text { ModelC } \\
\text { Con. }\left(\mathrm{cm}^{-3}\right)\end{array}$ & \multicolumn{1}{l|}{$\begin{array}{l}\text { ModelD } \\
\text { Con. }\left(\mathrm{cm}^{-3}\right)\end{array}$} & \multicolumn{1}{l|}{$\begin{array}{l}\text { ModelE } \\
\text { Con. }\left(\mathrm{cm}^{-3}\right)\end{array}$} \\
\hline water soluble & 3500.0000 & 4000.0000 & 4500.0000 & 5000.0000 & 5500.0000 \\
\hline Soot & 5000.0000 & 5000.0000 & 5000.0000 & 5000.0000 & 5000.0000 \\
\hline sea salt (acc) & 20.0000 & 20.0000 & 20.0000 & 20.0000 & 20.0000 \\
\hline sea salt (coa) & 0.0032 & 0.0032 & 0.0032 & 0.0032 & 0.0032 \\
\hline
\end{tabular}


BAJOPAS Volume 9 Number 2 December, 2016

Table2 :Microphysical properties of aerosol components at 0\% RH (Hess et al., 1998).

\begin{tabular}{lrrrr} 
Components & $\mathrm{R}_{\min }(\mu \mathrm{m})$ & $\mathrm{R}_{\max }(\mu \mathrm{m})$ & \multicolumn{1}{l}{ Sigma } & $\mathrm{R}_{\bmod }(\mu \mathrm{m})$ \\
\hline water soluble & 0.0050 & 20.0000 & 2.2400 & 0.0212 \\
Soot & 0.0050 & 20.0000 & 2.0000 & 0.0118 \\
sea salt (acc) & 0.0050 & 20.0000 & 2.0300 & 0.2090 \\
sea salt (coa) & 0.0050 & 60.0000 & 2.0300 & 1.7500 \\
\hline
\end{tabular}

Table 3:The results of the regression analysis of equation (6), the effective radii of the aerosols at $0 \% \mathrm{RH}$ using equation (5).

equation (6)

\begin{tabular}{lrrrr} 
& \multicolumn{2}{c}{$\begin{array}{l}\text { A=Kelvin } \\
\text { radii }(\mu \mathrm{m})\end{array}$} & $\begin{array}{l}\text { B=Bulk } \\
\text { hygroscopicity } \\
\text { factor }\end{array}$ & \multicolumn{1}{l}{$\begin{array}{l}\text { Effective radii } \\
\text { at } 0 \% \mathrm{RH}(\mu \mathrm{m})\end{array}$} \\
\hline ModelA & 0.9901 & 0.048415 & 2.012913 & 0.556633 \\
ModelB & 0.9902 & 0.047928 & 1.986528 & 0.550215 \\
ModelC & 0.9903 & 0.047482 & 1.961530 & 0.544083 \\
ModelD & 0.9904 & 0.047038 & 1.937194 & 0.538194 \\
ModelE & 0.9905 & 0.046610 & 1.913666 & 0.532565 \\
\hline
\end{tabular}

From Table 3,by observing the values of $\mathrm{R}^{2}$, it can be seen that the data fitted the model very well. It can also be observe that the Kelvin radiiand Bulk hygroscopicity factors decrease with the increase in the water soluble concentrations. This is because by looking at equation (3), it can be observe that the
Kelvin radii is proportional to the surface tension and this implies decrease in surface tension, while for B, it can be observe that it is inversely proportional to the volume of the solute. It can also be observe that the effective radii at $0 \% \mathrm{RH}$ decreases with the increase in water soluble.

\section{Table 4: The results of the regression of equation (13), using the ambient RHs and the water} activity.

\begin{tabular}{lrr}
\hline Models & \multicolumn{2}{c}{$\mathrm{R}^{2}$} \\
\hline ModelA & 0.9883 & 0.3502 \\
ModelB & 0.9886 & 0.3493 \\
ModelC & 0.9889 & 0.3484 \\
ModelD & 0.9891 & 0.3475 \\
ModelE & 0.9894 & 0.3466 \\
\hline
\end{tabular}

From Table 4, by observing the values of $\mathrm{R}^{2}$, it can be seen that the data fitted the model very well. By observing the values of $\mathrm{N}$, it can be seen that it decreases with the increase in water soluble concentrations. This signifies inverse relation between the effective growth, $g_{\text {eff }}$ and the equilibrium water saturation ratio, $\mathrm{S},(1-\mathrm{S})$.

Table 5: The results of the regression of equation (18), using the ambient RHs the water activity.

\begin{tabular}{lll}
\hline Equation (18) & $\mathrm{R}^{2}$ & $\mathrm{~K}$ \\
\hline ModelA & 0.9983 & 1.0329 \\
ModelB & 0.9983 & 1.0246 \\
ModelC & 0.9984 & 1.0164 \\
ModelD & 0.9984 & 1.0084 \\
ModelE & 0.9985 & 1.0005 \\
\hline
\end{tabular}

From Table 5 , by observing the values of $\mathrm{R}^{2}$, it can be seen that the data fitted the model very well. It can also be seen that the values of $k$ decrease with the increase in water soluble. This signifies increase in the effective hygroscopic growth with water soluble. 


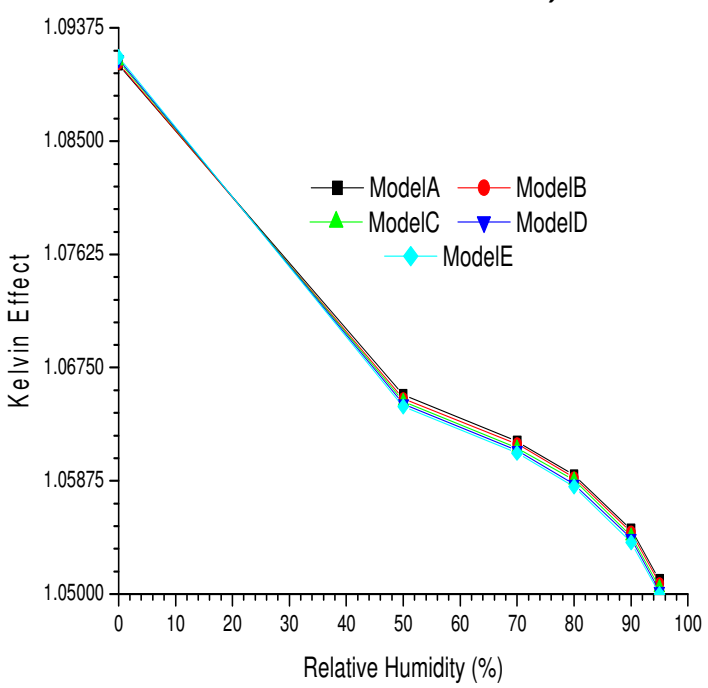

Figure1: A plot of Kelvin effect of the aerosols against Relative Humidity using equation (7b).

From Figure 1, it can be seen that kelvin effect decreases with the increase in RH. It also decreases with the increase in the water soluble concentrations most notably at higher RHs.

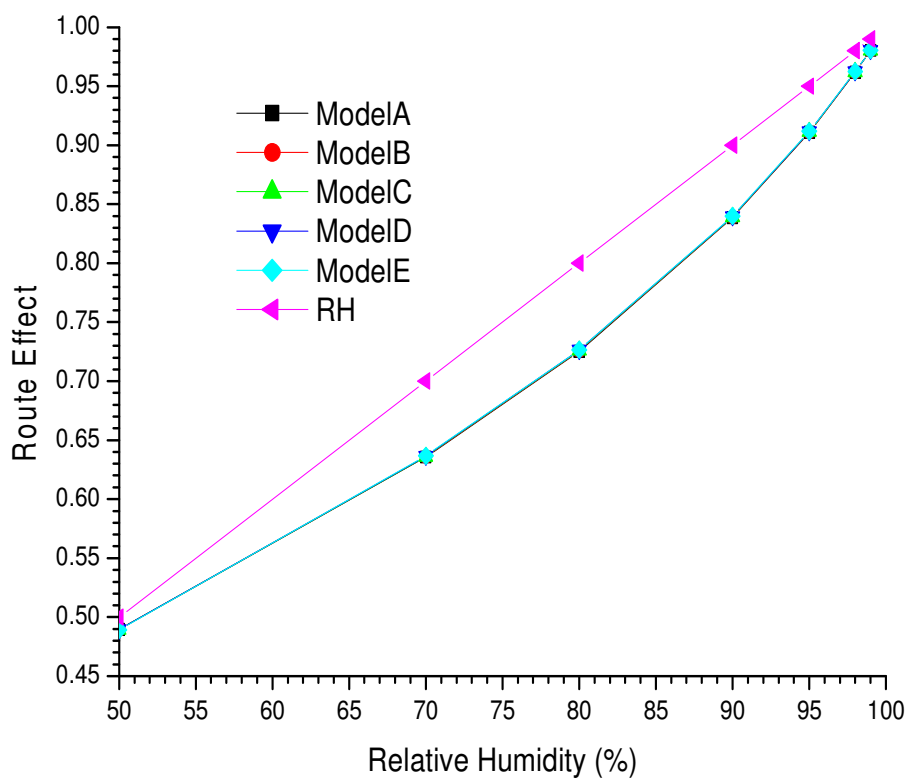

Figure 2: A plot of Route effect (water activity) of the aerosols against Relative Humidity using equation (8b).

From Figure 2, it can be seen that increase RHcaused increase in water activity and increase inwater soluble concentration has little effect on the Route effect. It increases with the increase in $\mathrm{RH}$ in almost quadratic form. It is also less than the ambient RH. This also signifies the importance of water activity in the ambient $\mathrm{RH}$, most especially at intermediate $\mathrm{RH}$. 
BAJOPAS Volume 9 Number 2 December, 2016

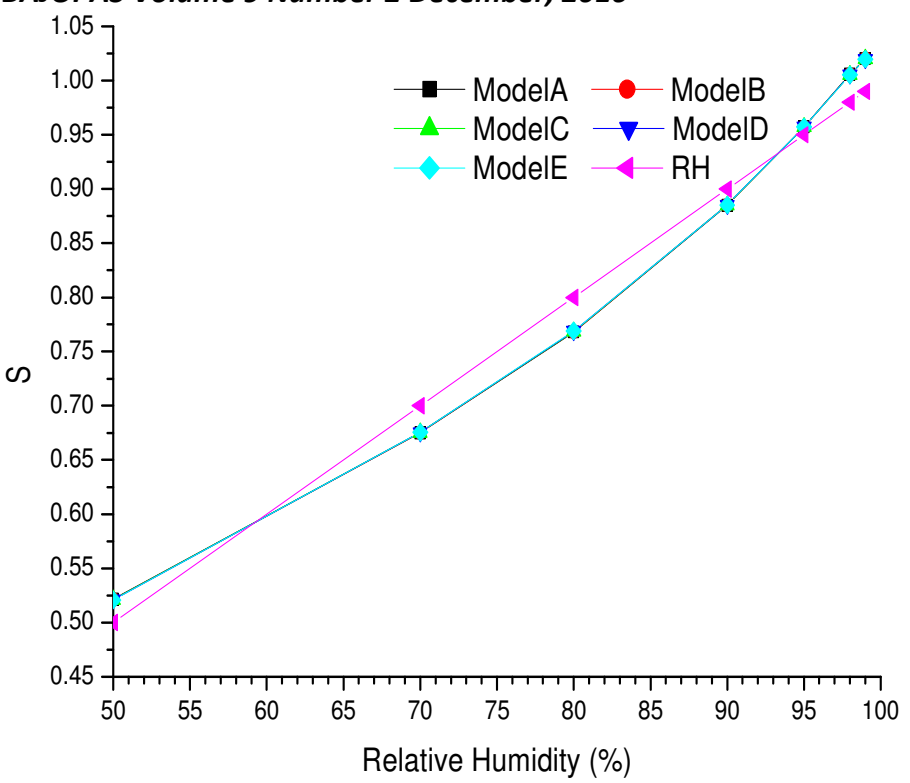

Figure3: $A$ plot of $S(R H)$ of the aerosols against Relative Humidity using equation (9).

From Figure 3, comparing Figure 3 with Figures 1 and 2, it can be seen that at RHs 50, 95, 98 and 99 Kelvin effect dominated, but at RHs 70, 80, and 90, the route effect dominated. It also shows the importance of water activity at the intermediate $\mathrm{RH}$.

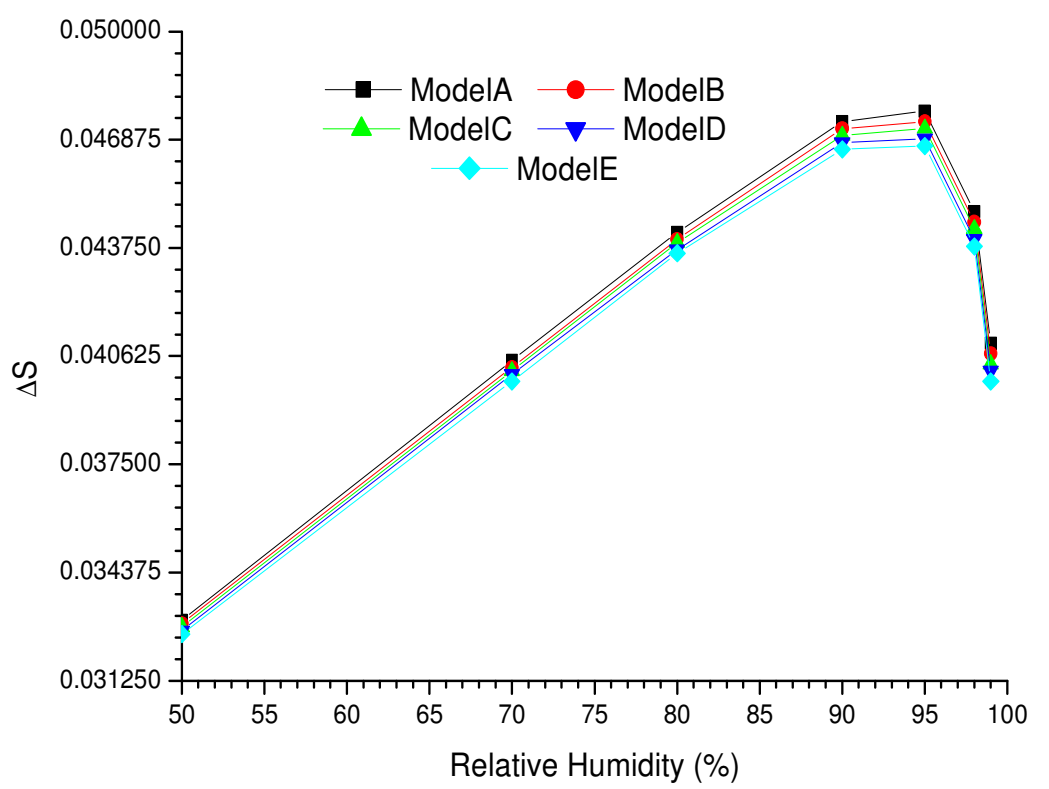

Figure4: A plot of $\triangle S$ of the aerosols against Relative Humidity using equation (10).

Figure 4 , shows the amount by which the equilibrium relative humidity of a given model is underestimated due to Kelvin effect. From the figure, it can be seen that it decreases with the increase in water solublesand is very sensitive with the increase in the ambient $\mathrm{RH}$. It is in the range of between 0.033 to 0.05.This shows that the more dilute the solution is, the more the underestimation due to kelvin effect. 
BAJOPAS Volume 9 Number 2 December, 2016

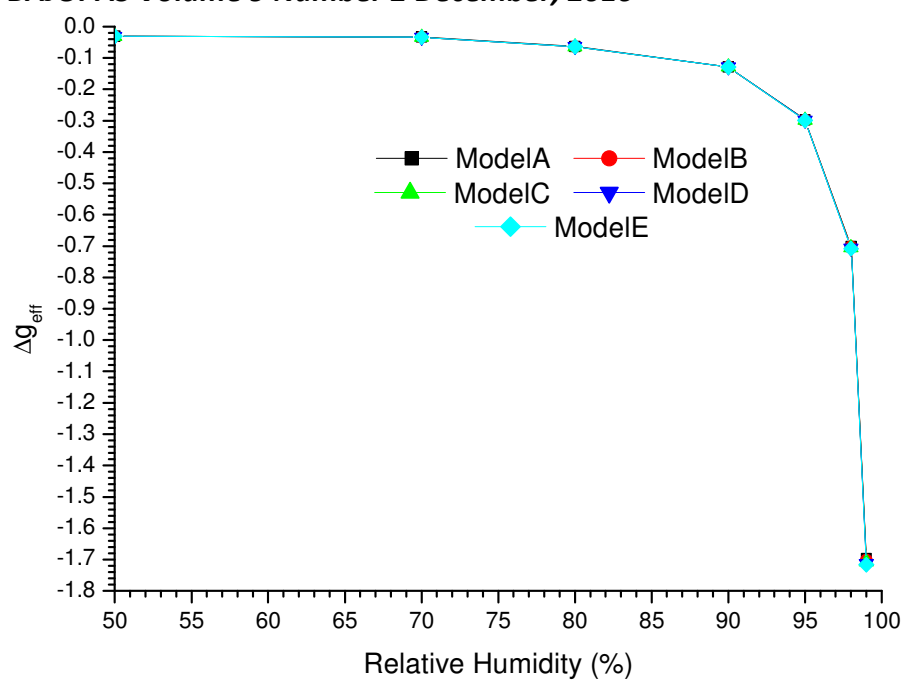

Figure 5: A plot of $4 g_{\text {eff }}$ of the aerosols against Relative Humidity using equation (11).

Figure 5 shows the amount by which the equilibrium effective hygroscopic growth of the models are overestimated by Kelvin effect. From the figure, it can

increase in the concentrations of the water solubles, but is very sensitive to RH most especially from the be observe that it increases very little with the intermediate to higher RHs.

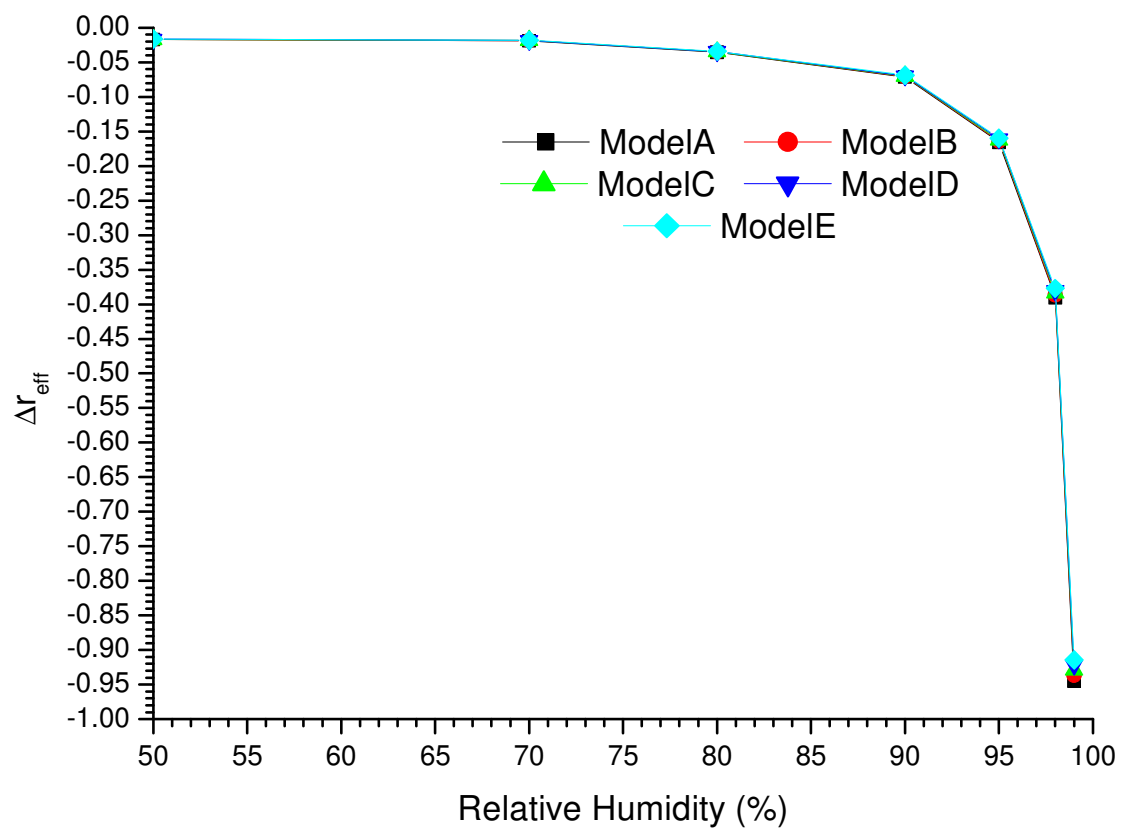

Figure 6: A plot of $\Delta r_{\text {aff }}$ of the aerosols against Relative Humidity using equation (12).

Figure 6 shows the amount by which the equilibrium effective radii of the models are overestimated due to Kelvin effect. From the plots, it can be seen that it decreases very little with the increase in the concentration of the water solubles, but is very sensitive to $\mathrm{RH}$ most especially from the intermediate to higher RHs. 
BAJOPAS Volume 9 Number 2 December, 2016

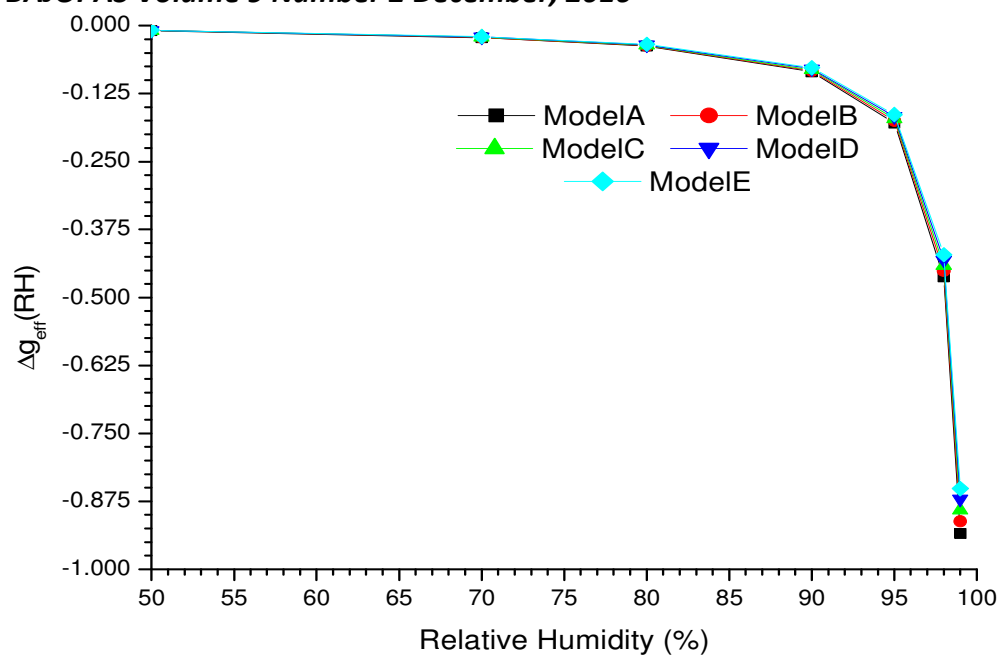

Figure 7: A plot of $\Delta g_{\text {eff }}(R H)$ of the aerosols against Relative Humidity using equation (14).

Figure 7 shows the amount by which the equilibrium effective hygroscopic growth of a given model is overestimated by Kelvin effect for our models of equation (13). From the figure it can be seen that the

overestimation decreased with the increase in the water soluble concentrations most especially at higher $\mathrm{RH}$.

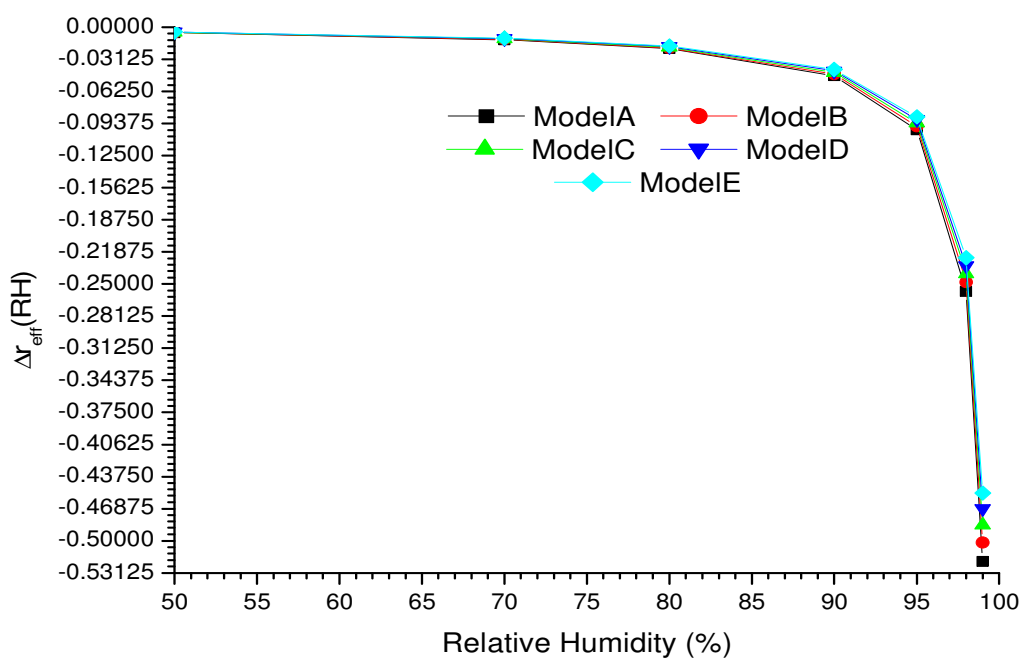

Figure8: $A$ plot of $\Delta r_{e f f}(R H)$ of the aerosols against Relative Humidity using equation (15).

Figure 8 shows the amount by which the equilibrium effective radii of the various models are over estimated when Kelvin effect is neglected from equation (13). From the figure it can be seen that the overestimation decreases with the increase in the concentrations of water soluble and is more important at higher RHs. 
BAJOPAS Volume 9 Number 2 December, 2016

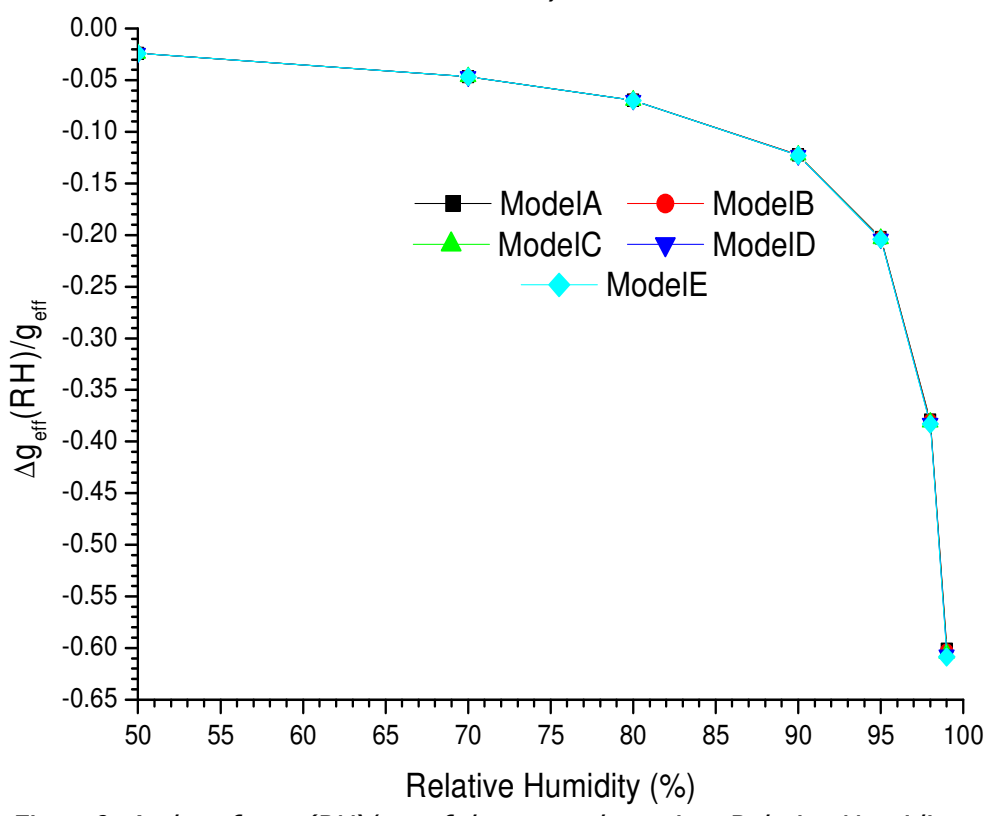

Figure9: A plot of $\Delta g_{\text {eff }}(R H) / g_{\text {eff }}$ of the aerosols against Relative Humidity using equation (16).

Figure 9 shows the plots of the fractional change in be seen that the fractional overestimation increases the effective hygroscopic growth when Kelvin effect is with the increase in water soluble concentration most neglected from equation (13). From the figure it can especially at higher RHs.

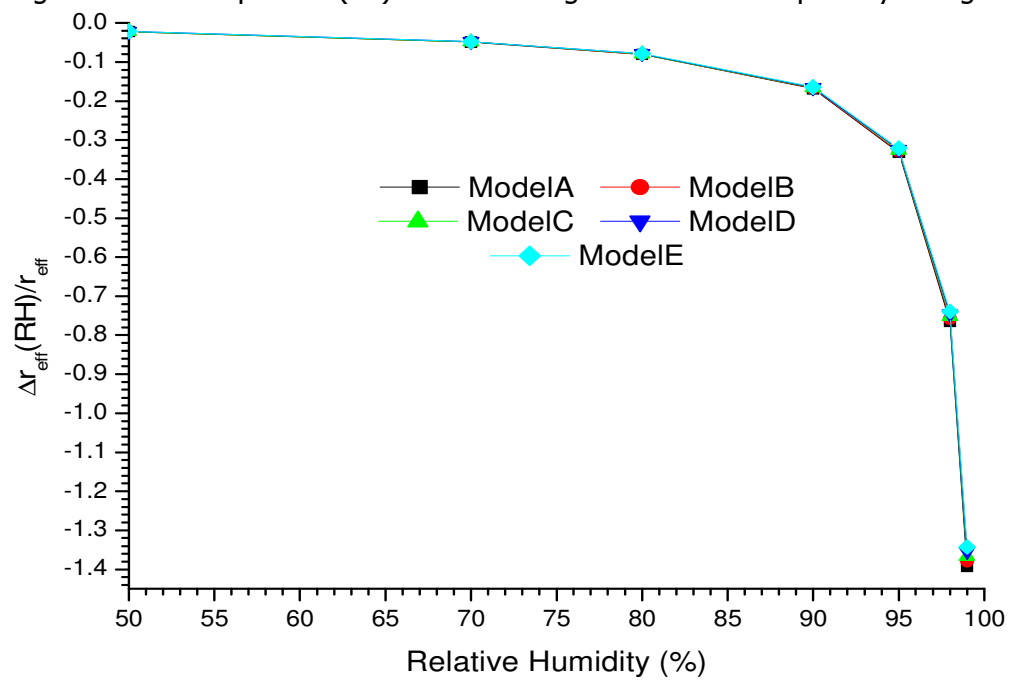

Figure 10: A plot of $\Delta r_{\text {eff }}(R H) / r_{\text {effof }}$ the aerosols against Relative Humidity using equation (17).

Figure 10 shows the plots of the fractional change in the effective radius when Kelvin effect is neglected from equation (13). From the figure it can be seen that the fractional overestimation decreases with the increase in water soluble concentration most especially at higher RHs. 
BAJOPAS Volume 9 Number 2 December, 2016

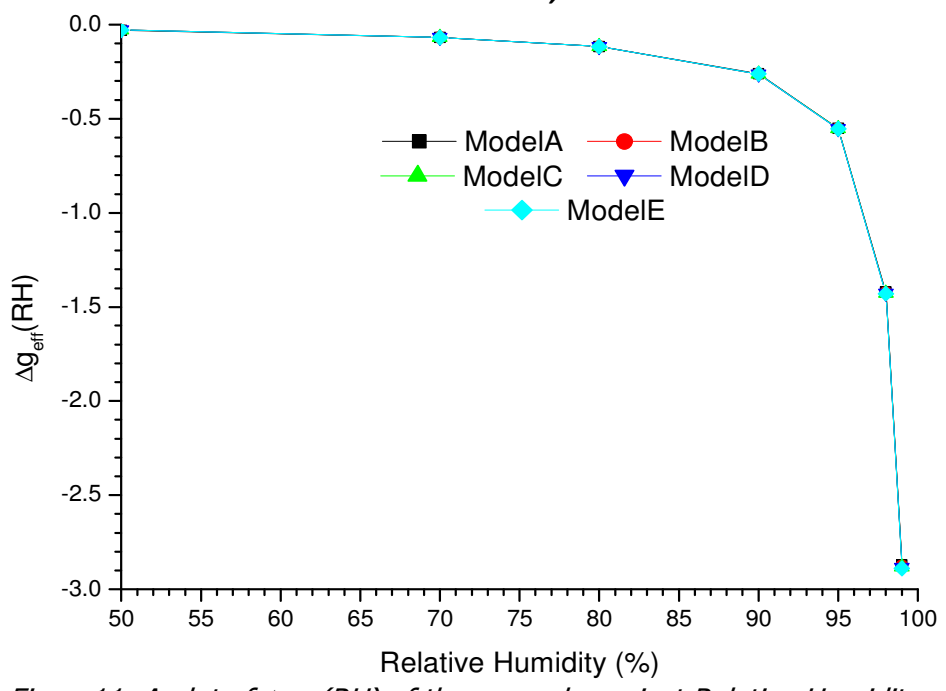

Figure11: A plot of $\Delta g_{\text {eff }}(R H)$ of the aerosols against Relative Humidity using equation (19).

Figure 11 shows the amount by which the equilibrium be seen that the error due to the Kelvin effect effective hygroscopic growth of a given mixture of increases with the increase in water soluble aerosols is overestimated when Kelvin effect is concentration mostespecially at higher RHs. neglected from equation (18).From the figure it can

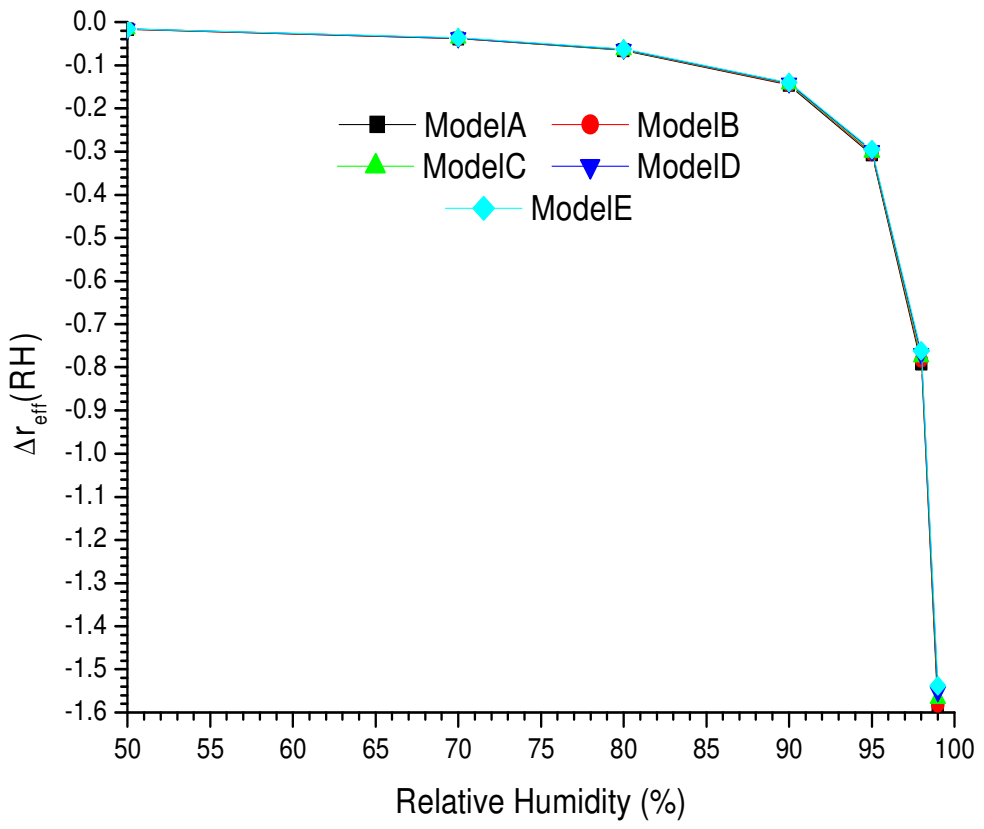

Figure12: A plot of $\Delta r_{\text {eff }}(R H)$ of the aerosols against Relative Humidity using equation (20).

Figure 12 shows the amount by which the equilibrium effective radius of a given mixture of aerosols is overestimated when Kelvin effect is neglected from equation (18). From thefigure it can be seen that the error decreases with the increase in the concentration of water soluble most especially at higher RHs. 
BAJOPAS Volume 9 Number 2 December, 2016

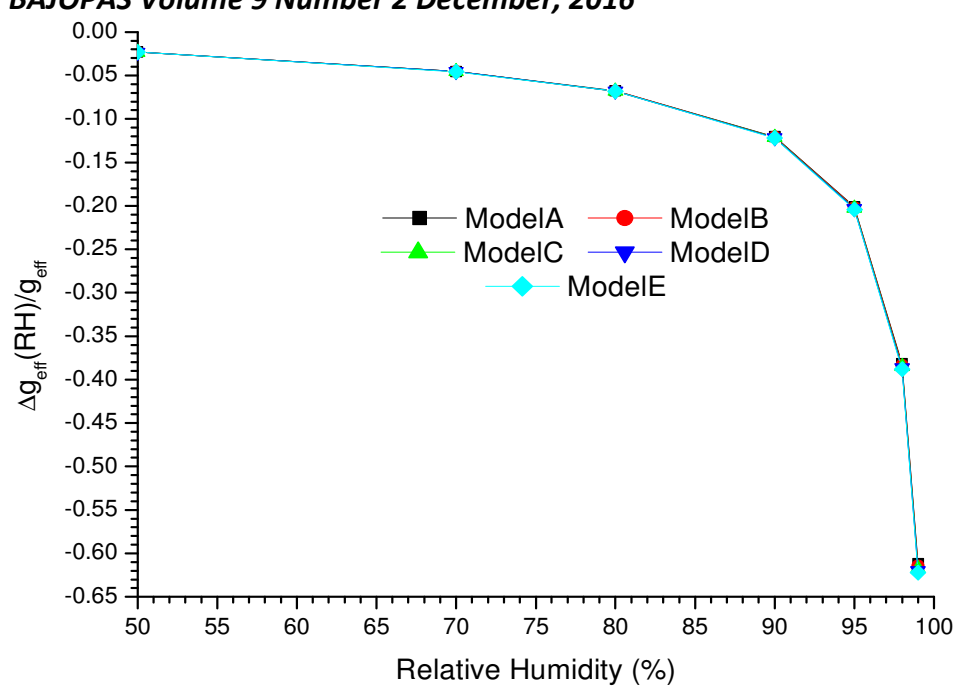

Figure13: A plot of $\Delta g_{\text {eff }}(R H) / g_{\text {eff }}$ of the aerosols against Relative Humidity using equation (21).

Figure 13 shows the amount by which the equilibrium equation (18). From the figure it can be seen that the fractional effective hygroscopic growth of are error increases with the increase in the concentration overestimated when Kelvin effect is neglected from of water solubles most especially at the higher RHs.

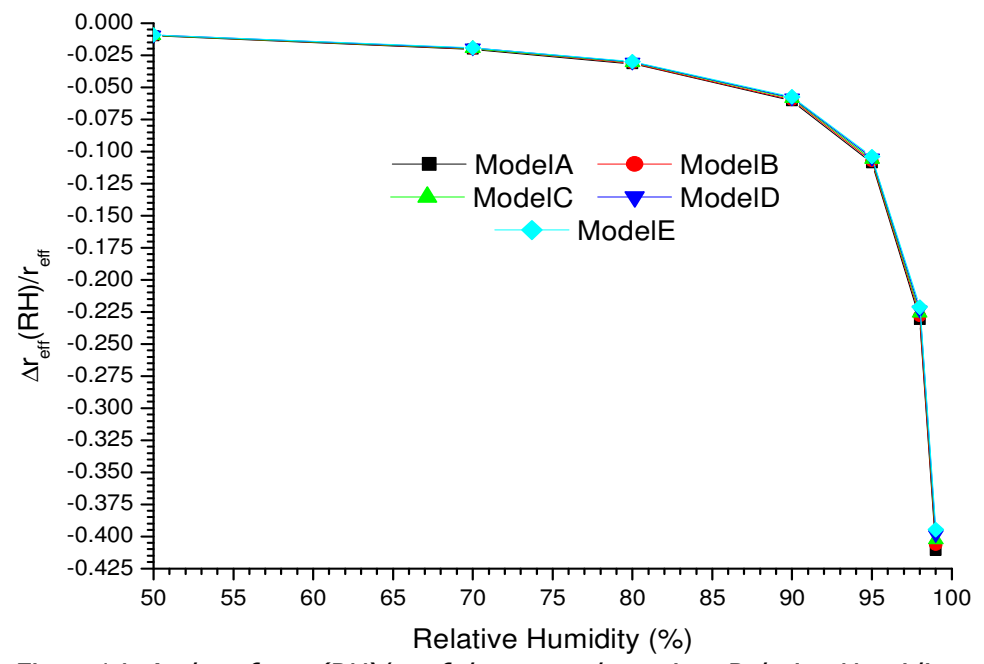

Figure14: A plot of $\Delta r_{\text {eff }}(R H) / r_{\text {effof }}$ the aerosols against Relative Humidity using equation (22).

Figure 14 shows the amount by which the equilibrium fractional effective radius of a given mixture of aerosols is overestimated when Kelvin effect is neglected from equation (18). From the figure it can observed that it decreases with the increase in the concentration of water solubles, most especially at higher RHs. 
BAJOPAS Volume 9 Number 2 December, 2016

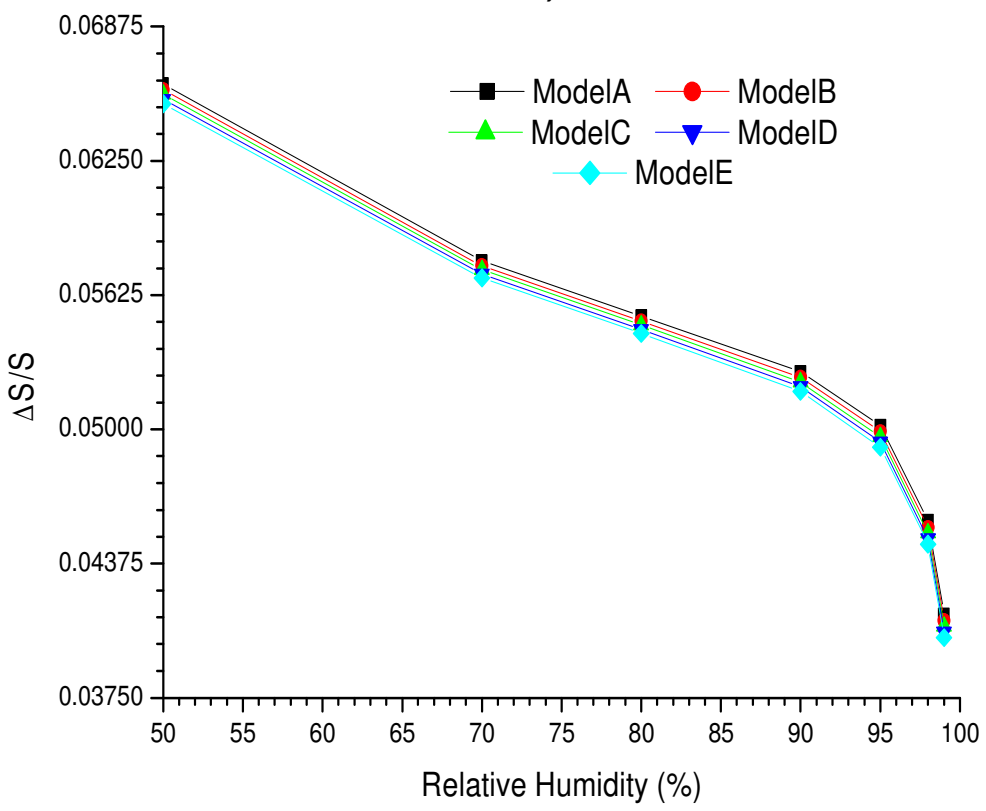

Figure15: A plot of $\Delta S / S$ of the aerosols against Relative Humidity using equation (23).

Figure 15 shows the plots of the fractional change in the ambient RH due to the Kelvin effect from equation (9). Form the figure it can be seen that the error decreases with the increase in the concentration of water soluble.

\section{CONCLUSION}

From the observations of the results obtained it can be concluded that increase in the concentrations of water soluble in aerosols has a great impact on its

\section{REFERENCES}

Anttila, T., Kerminen, V.M., 2002. Influence of organic compounds on the cloud droplet activation: a model investigation considering the volatility, water solubility, and surface activity of organic matter. J. Geophys. Res. 107 (D22), 4662.doi:10.1029/2001JD001482.

Birmili, W., Nowak, A., Schwirn, K., Lehmann, K.et al. (2004).A new method to accurately relate dry and humidified number size distributions of atmospheric aerosols.Journal of Aerosol Science, 1, 15-16.

Biskos, G., Paulsen, D., Russell, L. M., Buseck, P. R., and Martin, S. T.: Prompt deliquescence and efflorescence of aerosol nanoparticles, Atmos. Chem. Phys., 6, 4633-4642, doi:10.5194/acp-6-4633-2006, 2006a.

Biskos, G., Russell, L. M., Buseck, P. R., and Martin, S. T.: Nano-size effect onthe hygroscopic growth factor of aerosol particles, Geophys. Res. Lett., 33, L07801,doi:10.1029/2005GL025199, 2006b.

Christensen, S. I. and Petters, M. D. (2012).The role of temperature in cloud droplet activation.Journal of Physical Chemistry A,116(39), 9706-9717.

Gunthe, S. S., King, S. M., Rose, D., Chen, Q., Roldin, P., Farmer, D. K., Jimenez, J. L., Artaxo, P., Andreae, M. O., Martin, S. T., and P"oschl, effective radii, effective hygroscopic growth, in the ambient RHs, and their corresponding error due to the Kelvin effects.

However, there are some researchers that reported an erroneous implementation of the hygroscopic growth within OPAC, especially at intermediate $\mathrm{RH}$ ranges with the exception of Saharan dust (Zieger et al., 2013). This can probably be attributed to the behavior of Figure 2 of equation (8).

U.(2009). Cloud condensation nuclei in pristine tropical rainforest air of Amazonia: size-resolved measurements and modeling of atmospheric aerosol composition and CCN activity.Atmospheric Chemistry and Physics, 9, 7551-7575, doi:10.5194/acp-9-75512009.

Gysel, M., McFiggans, G. B., and Coe, H. (2009).Inversion of tandem differential mobility analyser (TDMA) measurements, Journal of Aerosol Science, 40, 134-151.

Gysel, M., Weingartner, E., and Baltensperger, U. (2002): Hygroscopicityof aerosol particles at low temperatures. 2. Theoretical and experimental hygroscopic properties of laboratory generated aerosols. Environmental Science and Technology, 36, 63-68.

Koepke P., Hess M., and Schult I (May 1997), Optical Properties of Aerosols and Clouds: The Software Package OPAC.Bulletin of the American Meteorological Society, 79, 5, 831844.

Kasten, F. (1969). Visibility forecast in the phase of pre-condensation. Tellus, XXI, 5, 631-635.

Kohler, H.: (1936). The nucleus in and the growth of hygroscopic droplets. Transaction of Faraday Society, 32, 1152-1161. 
Kreidenweis S. M., K. Koehler, P. J. DeMott, A. J. Prenni, C. Carrico, and B. Ervens (2005) Water activity and activation diameters from hygroscopicity data -Part I: Theory and application to inorganic salts, Atmospheric Chemistry Physics, 5, 1357-1370, www.atmos-chemphys.org/acp/5/1357/SRef-ID: 16807324/acp/2005-5-1357.

Lewis E. R. (2006), The effect of surface tension (Kelvin effect) on the equilibriumradius of a hygroscopic aqueous aerosol particle, Journal of Aerosol Science, 37, 1605 - 1617, www.elsevier.com/locate/jaerosci.

Laaksonen, A., Korhonen, P., Kulmala, M., and Charlson, R. J.(1998): Modification of the Kohler equation to include soluble trace gases and slightly soluble substances, J. Atmos. Sci., 55 (5), 853-862.

Martin,S.T. (2000),

Phasetransitions ofaqueousatmosphericparticles,Chem.Rev., 100, 3403-3453.

McFiggans, G., Artaxo, P., Baltensperger, U., Coe, H., Facchini, M. C., Feingold, G., Fuzzi, S.,Gysel, M., Laaksonen, A., Lohmann, U., Mentel, T. F., Murphy, D. M., O'Dowd, C. D., Snider, J. R., and Weingartner, E (2006).: The effect of physical and chemical aerosol properties on warmcloud droplet activation, Atmos. Chem. Phys., 6, 2593-2649, doi:10.5194/acp-62593-2006,.

Meyer, N. K., Duplissy, J., Gysel, M., Metzger, A., Dommen, J., Weingartner, E., Alfarra, M. R., Prevot, A. S. H., Fletcher, C., Good, N., McFiggans, G., Jonsson, A. M., Hallquist, M., Baltensperger, U., and Ristovski, Z. D. (2009): Analysis of the hygroscopic and volatile properties of ammonium sulphate seeded and unseeded SOA particles.Atmospheric. Chemistry and Physics, 9, 721-732, doi:10.5194/acp-9-7212009.

Mikhailov, E., Vlasenko, S., Martin, S. T., Koop, T., and P " oschl, U.(2009): Amorphous and crystalline aerosol particles interacting with water vapor: conceptual framework and experimental evidence for restructuring, phase transitions and kinetic limitations, Atmos. Chem. Phys., 9,9491-9522, doi:10.5194/acp-9-9491-2009.

Mikhailov, E., Vlasenko, S., Niessner, R., and P *. oschl, U.(2004): Interaction of aerosol particles composed of protein and saltswith water vapor: hygroscopic growth and microstructural rearrangement, Atmos. Chem. Phys., 4, 323-350, doi:10.5194/acp4-323-2004.

Mochida M.,Kuwata M., Miyakawa T., Takegawa N.,Kawamura K., and Kondo Y. (2006) Relationship between hygroscopicity and cloud condensation nucleiactivity for urban aerosols in Tokyo.Journal of Geophysical
Research, 111,
doi:10.1029/2005JD006980

Nenes, A., Charlson, R. J., Facchini, M. C., Kulmala, M., Laaksonen, A., and Seinfeld, J. H.(2002): Can chemical effects on cloud droplet number rival the first indirect effect?, Geophys. Res. Lett., 29 (17), art.no. 1848.

Petters, M. and Kreidenweis, S.: (2007) A single parameter representation of hygroscopic growth and cloud condensation nucleus activity.Atmospheric Chemistry and Physics, 7, 1961-1971, doi:10.5194/acp-7-19612007.

Pruppacher, H. R., and J. D. Klett (1997),Microphysics of Clouds andPrecipitation, 2nd ed., 954 pp., Springer, New York.

Putaud, J. P. (2012): Interactive comment on "Aerosol hygroscopicity at Ispra EMEP-GAW station" by M. Adam et. al., Atmospheric Chemistry and Physics, Discussions, 12, C1316-C1322.

Rose, D., Gunthe, S. S., Mikhailov, E., Frank, G. P., Dusek, U., Andreae, M. O., and P ". oschl, U(2008)::Calibration and measurement uncertainties of a continuous-flow cloud condensation nuclei counter (DMT-CCNC): $\mathrm{CCN}$ activation of ammonium sulfate and sodium chloride aerosolparticles in theory and experiment, Atmos. Chem. Phys., 8, 1153-1179, doi:10.5194/acp-8-1153-2008.

Ruehl, C. R., Chuang, P. Y., and Nenes, A.(2010): Aerosol hygroscopicity at high (99 to $100 \%$ ) relativehumidities, Atmos. Chem. Phys., 10, 1329-1344, doi:10.5194/acp-10-1329-2010.

Russell, L. M., \& Ming, Y. (2002). Deliquescence of small particles.Journal of Chemical Physics,116(1), 311-321.

Seinfeld, J. H. and Pandis, S. N(2006).: Atmospheric chemistry and physics, J. Wiley and Sons, Inc., New York.

Seinfeld, J. H. and Pandis, S. N.: Atmospheric chemistry and physics, J. Wiley and Sons, Inc., New York, 1998.

Sjogren, S., Gysel, M., Weingartner, E., Baltensperger, U., Cubi-son, M. J., Coe, H., Zardini, A. A., Marcolli, C., Krieger, U. K., and Peter, T.( 2007): Hygroscopic growth and water uptake kinetics of two-phase aerosol particles consisting of ammonium sulfate, adipic and humic acid mixtures. Journal of Aerosol Science, 38, 157-171.

Stock M., Y. F. Cheng, W. Birmili, A. Massling, B. Wehner, T. Muller, S. Leinert, N. Kalivitis,N. Mihalopoulos, and A. Wiedensohler, (2011). Hygroscopic properties of atmospheric aerosol particles over the Eastern Mediterranean: implications for regional direct radiative forcing under clean and polluted conditions.Atmospheric Chemistry and Physics., 11, 4251-4271, www.atmoschem-phys.net/11/4251/2011/ doi:10.5194/acp-11-4251-2011.

Stokes, R. H. and Robinson, R. A. (1966).Interactions in aqueous nonelectrolyte solutions. I. Solute-solvent equilibria.Journal of Physical Chemistry, 70, 2126-2130. 
BAJOPAS Volume 9 Number 2 December, 2016

Sun, J.M., Ariya, P.A., 2006. Atmospheric organic and bio-aerosols as cloud condensation nuclei (CCN): a review. Atmos. Environ. 40 (5), 795-820.

Sullivan, R. C., S. A. Guazzotti, D. A. Sodeman, and K. A. Prather, 2007: Direct observations of the atmospheric processing of asian mineral dust. Journal of Atmospheric Chemistry and Physics, 7(5), 1213-1236, doi:10.5194/acp7-1213-2007

Swietlicki, E., Zhou, J.C., Covert, D.S., et al., 2000.Hygroscopic properties of aerosolparticles in the north-eastern Atlantic during ACE-2.Tellus 52, 201-227.

Tijjani,B.I.,Galadanci, G.S.M., Abubakar,A.I.,Koki, F. S.,Adamu, I. D.,Nura, A. M.,Saleh,M., Uba,S.(2015): The Effect of Kelvin Effect On The Equilibrium Effective Radii And Hygroscopic Growthof Atmospheric Aerosols. IISTE- Journal of Natural Sciences Research, Vol.5, No.22, 2015 p96-111.

Tijjani B. I. (2013a), The Effect of Soot and Water Soluble on the Hygroscopicity of Urban Aerosols, Advances in Physics Theories and Applications, Vol.26, p52-72.

Tijjani B. I. and Uba S. (2013a), The Effect Of Hygroscopic Growth On Urban Aerosols, The International Institute for Science, Technology and Education (IISTE), Vol.25, 2013, pp58-75.
Tijjani B. I. and Uba S. (2013b) The effect of hygroscopic growth on desert aerosols, Pelagia Research Library, Advances in Applied Science Research, 2013, 4(4):465478.

Tijjani B. I., (2013b), The Effect Of Water Solubles On The Hygroscopicity Of Urban Aerosols, International Journal of Computational Engineering Research, (IJCER) Vol, 03, Issue, 11, 45-60.

Tijjani B. I., Aliyu A., Shuaibu F. (2013), The Effect of Hygroscopic Growth on Continental Aerosols, Open Journal of Applied Sciences, 2013, 3, 381-392; http://dx.doi.org/10.4236/ojapps.2013.3604 8.

ZiegerP., Fierz-Schmidhauser R., WeingartnerE. and Baltensperger U. (2013) Effects of relative humidity on aerosol light scattering:results from different European sites. Journal of Atmospheric Chemistry and Physics, 13, 10609-10631, www.atmos-chemphys.net/13/10609/2013/, doi:10.5194/acp13-10609-2013. 